\title{
Deriving Clinically Meaningful Cut-scores for Fatigue in a Cohort of Breast Cancer Survivors: a Health, Eating, Activity, and Lifestyle (HEAL) Study
}

\author{
Angela M. Stover ${ }^{1}$, Bryce B. Reeve ${ }^{1,{ }^{*}}$, Barbara F. Piper ${ }^{2}$, Catherine M. Alfano ${ }^{3}$, Ashley \\ Wilder Smith ${ }^{3}$, Sandra A. Mitchell ${ }^{3}$, Leslie Bernstein ${ }^{4}$, Kathy B. Baumgartner ${ }^{5}$, Anne \\ McTiernan $^{6}$, and Rachel Ballard-Barbash ${ }^{3}$ \\ ${ }^{1}$ University of North Carolina-Chapel Hill \\ ${ }^{2}$ National University \\ ${ }^{3}$ National Cancer Institute \\ ${ }^{4}$ City of Hope National Medical Center \\ 5 University of Louisville \\ ${ }^{6}$ Fred Hutchinson Cancer Research Center
}

\begin{abstract}
Keywords
cancer-related fatigue; breast cancer survivors; measurement; Piper Fatigue Scale; health-related quality of life
\end{abstract}

\section{Introduction}

Cancer-related fatigue (CRF) is increasingly recognized by clinicians, researchers, and survivors as a debilitating symptom requiring clinical attention that may negatively impact quality of life [1-4]. At the same time, there is evidence that CRF continues to be underevaluated and under-treated [5-8]. Guidelines for the clinical management of CRF have been developed by the National Cancer Institute (NCI), National Comprehensive Cancer Network (NCCN), the Fatigue Coalition, and other task force organizations [9-15]. The NCCN guidelines recommend utilizing a single item with a $0-10$ severity metric to screen for CRF but consensus for determining clinically meaningful thresholds for categorizing cancer patients as experiencing mild, moderate, or severe fatigue is in its infancy [10-11].

More than twenty patient-reported measures of fatigue are in use in oncology research and practice to assess both the fatigue experience and impact of fatigue on health-related quality of life (HRQOL) [16-22]. To enhance consistency and precision in population-based and clinical research, fatigue scores need to be interpreted using clinically meaningful threshold descriptions that accurately characterize the level of CRF and its impact on HRQOL.

Several studies have demonstrated that baseline fatigue severity scores can predict fatigue

*Corresponding author: Bryce B. Reeve, PhD, Associate Professor, Health Policy \& Management, University of North Carolina at Chapel Hill, 1101-D McGavran-Greenberg Hall, Campus Box 7411, Chapel Hill, NC 27599-7411, T: 919-843-8793, F:

919-843-6362, bbreeve@email.unc.edu.

Portions of this manuscript were presented at the 2012 annual meetings for the Society of Behavioral Medicine (SBM) and the International Society of Quality of Life (ISOQOL)

Disclaimers: None 
severity levels over time in patients on active treatment [4, 23-24]. Thus, classifying patients into severity thresholds at baseline and following these levels over time is becoming increasingly important in practice and research.

Conventionally in practice, a fatigue severity cut-score of $\geq 4$ on a $0-10$ scale has been used as a cut-off score to make treatment decisions [e.g., 18]. However, empirical derivations of clinically meaningful cut-points of mild, moderate, and severe fatigue are limited. Each threshold level may have implications for risk-stratification into levels of clinical care such as when intervention with medication to reduce fatigue is warranted. For instance, Bupropion sustained-release and Modafinil are observed to reduce severe and impairing fatigue in cancer patients but their effects on mild or moderate CRF is less certain [25-28]. Further, classifying patients into fatigue levels can be used to better interpret response to treatments and optimize research designs through participant selection criteria. For example, the magnitude of change that can be demonstrated in response to an intervention is optimized by designs that select study participants across the continuum of fatigue [29].

Sexual functioning is also an important dimension of HRQOL that has been shown to be positively correlated with fatigue but the relationship is largely unexplored [30-31]. Similar to fatigue, sexual dysfunction is common yet under-recognized and under-treated [32-34]. Sexual dysfunction can also persist during survivorship despite recovery in other domains such as physical functioning [1,32-34]. The normal process of aging and loss of estrogen over time for postmenopausal women are known to impact sexual function with approximately $35 \%$ of older U.S. women reporting difficulty with orgasm and $44 \%$ reporting lack of sexual interest [35]. Beyond aging processes, breast cancer survivors have unique considerations such as chemotherapy-induced ovarian failure [30, 34, 36]. Women with hormone-receptor positive tumors may be advised to avoid postmenopausal estrogen therapy and may be prescribed tamoxifen to prevent estrogen from binding to breast cancer cells, which also may impact sexual function and fatigue [34].

With these considerations in mind, the aim of our study was to empirically determine clinically meaningful fatigue severity thresholds (cut-scores within a 0-10 scale metric) for the 22-item Piper Fatigue Scale-revised (PFS-R) [37] and its shortened 12-item version (PFS-12) [38] in a cohort of breast cancer survivors. The PFS-R and PFS-12 are multidimensional and include key dimensions of the fatigue experience including cognition, behaviors, affect, and sensory symptoms [37-38]. We examined five candidate models of fatigue severity thresholds where breast cancer survivors could be classified on the PFS-R or PFS-12 as none, mildly, moderately, or severely fatigued on a $0-10$ metric. We then examined the association of these ordered fatigue classifications with changes in HRQOL (physical, mental, and sexual health).

\section{Methods Participants}

The Health, Eating, Activity, and Lifestyle (HEAL) Study is prospectively following a multi-site cohort of women newly diagnosed with stages 0 -IIIa breast cancer [1, 39]. The HEAL study was designed to examine the influence of body mass, health behaviors, sex hormones, and genetic factors on long-term breast cancer outcomes. The HEAL Study enrolled 1,183 women from SEER (Surveillance, Epidemiology, and End Results) cancer registries in the United States who were diagnosed between 1995-1999. Comparisons between women enrolled in HEAL and women eligible in SEER have been published previously [39]. Of the 1,183 enrolled, 858 (73\%) completed a HRQOL battery approximately 3 years after diagnosis. Reasons for non-participation in the HRQOL assessment included death $(n=75)$, refusal to participate $(n=140)$, inability to contact $(n=99)$, 
and too ill to complete questionnaire $(n=11)$ [1]. In the current study, one woman with incomplete data was excluded resulting in a final sample size of 857 women.

Women were recruited from three SEER registries: New Mexico: 457 (53\%); Western Washington: 177 (21\%); and Los Angeles County: 223 (26\%). By design, the majority of African American survivors were enrolled at the Los Angeles County site and the majority of Hispanic survivors were enrolled at the New Mexico site [1,39]. In addition, each site had different age restrictions due to ongoing clinical trials (Los Angeles County: ages 3564; Western Washington: 40-64; and New Mexico: 218 ). In analyses, we controlled for both age and race/ethnicity to minimize potential differences across groups. Women who experienced a recurrence or new primary breast cancer were included in analyses $(n=57$ or $7 \%$ ) as research suggests that these women may be at risk for experiencing higher levels of fatigue [40]. In terms of measurement, having breast cancer survivors across the continuum of fatigue is desirable [29].

This study was approved by the Institutional Review Board at each site. Each woman provided informed consent to participate prior to enrollment.

\section{Data Collection}

The baseline assessment was completed as an in-person interview within one year of diagnosis with breast cancer. Women reported their age at diagnosis, level of education, racial and ethnic background, and height [1]. The follow-up HRQOL assessment occurred approximately 3 years after diagnosis (i.e., 2 years after baseline). At follow-up, survivors reported demographics, comorbid conditions, and medication use (including tamoxifen and antidepressants) and were weighed by staff $[1,39]$. HRQOL data included the 22-item PFSR [37], the Medical Outcome Study short form-36 questionnaire (SF-36) [41], and the Sexual Functioning subscale of the Cancer Inventory for Problem Situations (CIPS) [42]. Clinical data such as stage and treatment type were collected from SEER medical record abstraction [1,39].

The 22-item PFS-R, and its shorter version, the 12-item PFS-12, have 4 subscales: Behavioral, Affective, Sensory, and Cognitive [37-38]. Subscale scores are added together and divided by 4 to obtain a total fatigue score bound between 0 and 10 where higher scores reflect more fatigue [37-38]. The HEAL Study employed an adapted recall period for the PFS-R, asking survivors to rate their fatigue over the past month rather than the past week [1]. This extended recall period was intended to capture a general state of fatigue rather than acute episodes that may not be representative of survivors' overall fatigue experiences. The shorter PFS-12 was developed in a separate study using data from the same HEAL cohort by retaining items with the best psychometric properties including content validity [38]. Support was demonstrated for both an overall fatigue factor in the PFS-R and PFS-12 [38]. In the current study, Cronbach's alpha reliability for the PFS-R scale was .96 and .92 for the PFS-12.

The SF-36 has eight subscales (physical functioning, general health, role physical, bodily pain, mental health, role emotional, social functioning, and vitality) that range from $0-100$ where higher scores indicate better HRQOL [41]. Two component scores are calculated based on weights applied to the subscales: a Physical Component Summary (PCS) score and a Mental Component Summary (MCS) score [41, 43]. Scores are normalized to the general U.S. population on a T-score metric (mean of 50 and SD of 10) and a score change of a half standard deviation (5 points) has been demonstrated to be clinically meaningful [41, 43]. Population norms are provided for gender and age range categories [41, 43]. Cronbach's coefficient alpha reliability for the SF-36 subscales ranged from .78-.87. 
The Sexual Functioning subscale of the Cancer Inventory of Problem Situations (CIPS) is scored from 0 (not a problem) to 3 (serious problem) and higher scores indicate worse sexual functioning [42]. The CIPS sexual functioning subscale assesses physical and psycho-social aspects of sexual health including lack of sexual interest, difficulty in becoming aroused, inability to relax and enjoy sex, and difficulty in having an orgasm [42]. Given that no publications are available that assess clinically meaningful differences in CIPS scores, we used .3 to .5 of a standard deviation to define a minimally important difference [44-47]. Cronbach's coefficient alpha reliability for pre-diagnosis sexual functioning was .87 and post-diagnosis was .92 .

Comorbid conditions were assessed by asking each woman if a doctor or other health professional had ever informed her that she had each of 18 health conditions such as diabetes, cardiovascular disease, and arthritis [1]. Endorsement of a health condition was followed with a question assessing whether the condition limited activities. A comorbid health condition index was calculated by summing the number of health conditions that limit activities. Body mass index (BMI) was calculated as $\mathrm{kg} / \mathrm{m}^{2}$.

Clinical and treatment data were collected from the SEER cancer registries. The registries abstract clinical data from pathology reports about tumor size and grade, lymph node status, and hormone receptor status. HEAL provides a calculated variable for disease stage across versions of the American Joint Committee on Cancer (AJCC) Cancer Staging Manual that was applicable at the time of diagnosis [48].

\section{Analyses}

We examined five candidate models of fatigue severity thresholds (cut-scores within the 0 10 scale metric) where breast cancer survivors could be classified on the PFS-R and PFS-12 as none, mildly, moderately, or severely fatigued (see Figure 1). Model A reflected cutscores based on clinical judgment and historical use with the PFS-R [1, 39]. Model A is also consistent with thresholds identified on a similar fatigue measure, the Brief Fatigue Inventory [22]. Models B-E were generated by expanding and contracting the threshold categories based on clinical and measurement-related considerations.

To evaluate which of the five models yielded optimal cut-scores for fatigue severity on the PFS-R and PFS-12, we used multivariate analysis of covariance (MANCOVA) [49]. MANCOVA controls for inflation of the type I error rate by conducting an overall test of multiple dependent variables (with multiple covariates), and produces several F-values including Wilk's lambda, Pillai's trace, and Hotelling's trace [49]. Consistent with standard MANCOVA methodology and prior work on other fatigue scales, the highest combination of F-values was used to determine optimal threshold models that demonstrate the highest discrimination among fatigue levels [22]. Each model's fatigue severity cut-scores (i.e., Models A-E) were used as the between-subjects variable in the MANCOVA. Given that there is neither a gold standard nor objective way to measure fatigue such as a biomarker, the four SF-36 Vitality items were used as the dependent variables in the MANCOVA model. The SF-36 Vitality items include "feeling full of life," "worn out," "tired," and "have a lot of energy" [41]. The Vitality subscale has been shown to be high performing in terms of reliability, validity, and robust psychometric properties for use with breast cancer patients and survivors [50-52]. In addition, SF-36 scores are normalized to the U.S. population [41]. A previous HEAL Study analysis found a $79 \%$ concordance rate for classifying breast cancer survivors on fatigue using the SF-36 Vitality items and the PFS-R [1].

We then examined the association between identified cut-scores and decrements in HRQOL (SF-36 subscales and summary scores, and CIPS sexual functioning scale). The SF-36 
Vitality subscale was not reported as a single subscale outcome given that these items were used to determine cut-scores (but it is one component of the PCS and MCS calculations).

Multivariate regression was used to model the variation in HRQOL explained by fatigue, adjusting for demographic characteristics (age, race, education), treatment-related variables (stage, type of treatment, tamoxifen use), comorbid health conditions that limit activities, and antidepressant use to minimize potential differences across groups. These variables were chosen given their positive associations with fatigue in prior research and the HEAL sampling design [1, 39, 53-56]. Models with sexual functioning as an outcome variable also included baseline sexual functioning as a covariate. BMI was not significantly related to the PFS-R or PFS-12 and thus, was not used as a covariate (correlation $r=.04, p=.24$ and $r=$. $05, p=.15$; respectively).

\section{Results \\ Sample Characteristics}

The demographic and clinical characteristics for the 857 breast cancer survivors are provided in Table 1. Age at diagnosis ranged from 29-86 years with a mean of 55 $(\mathrm{SD}=10.31$ ). At baseline (within 1 year of diagnosis), $67 \%$ of women reported being nonHispanic Caucasian, $76 \%$ were post-menopausal, and $25 \%$ had completed high school or less education. The majority of survivors had been diagnosed as in situ or Stage I (62\%), had undergone a partial mastectomy including breast-conserving surgery (64\%), and had completed adjuvant therapy (68\%). Fifty-seven women (7\%) experienced a recurrence (or new primary breast cancer) between baseline and 3 years post-diagnosis. At the time of the HRQOL assessment (approximately 3 years after diagnosis), 57\% were working, over half of the cohort had a BMI of $25 \mathrm{~kg} / \mathrm{m}^{2}$ or more $(56 \%)$, and $72 \%$ reported one or more comorbid condition(s).

\section{Model Results}

The PFS-R and PFS-12 mean scores were 3.9 with a range from $0-9.92$ (SD 2.0). As expected, the correlation between the PFS-R and the SF-36 Vitality subscale was high ( $r=$ $-0.73, \mathrm{p}<.0001$; correlation with PFS-12: $\mathrm{r}=-0.73, \mathrm{p}<.0001)$. Table 2 includes adjusted MANCOVA results for the five candidate fatigue cut-score models in descending order by F-values. With the SF-36 Vitality items used as the dependent variables, Models A and D showed the highest magnitude of F values over Models B, C, and E. Thus, we will present results for only Models A and D for the PFS-R and PFS-12 in the rest of the paper.

\section{Associations of PFS-R and PFS-12 Fatigue Cut-Scores with HRQOL Decrements}

Mean scores for the SF-36 subscales ranged from 45.82 ( $\mathrm{SD}=11.06$, physical function) to 49.98 ( $\mathrm{SD}=10.80$, bodily pain). Correlations between the PFS-R and SF-36 subscales ranged from -0.35 (PFS-R and Physical Function, $p<0.01$ ) to -0.61 (PFS-R and MCS, $p<0.01$ ). Mean sexual functioning and the PFS-R were correlated at .27, $\mathrm{p}<.01$. Correlations between the PFS-12 and SF-36 Summary Scores ranged from -0.37 (PFS-12 and Physical Function, $p<0.01$ ) to -0.59 (PFS-12 and MCS, $p<0.01$ ). Mean sexual functioning and the PFS-12 were correlated at $.28, \mathrm{p}<.01$. All correlations were statistically significant at the .01 level and the magnitudes suggest moderate to strong associations between fatigue and HRQOL domains.

Figure 2 provides comparison graphics between Models A and D for the PFS-R and PFS-12 and incremental decrements in physical and mental functioning as fatigue thresholds increase. For both Models A and D, women classified as having no fatigue on the PFS-R and PFS-12 had the highest scores in every SF-36 domain and women classified as severe 
fatigue had the lowest scores. For Model A on the PFS-R and PFS-12, 8 out of 9 HRQOL domains demonstrated threshold values that were significantly different for breast cancer survivors for each level of none, mild, moderate, and severe fatigue (PCS, MCS, general health, bodily pain, role physical, mental health, social functioning, and role emotional).

The single case of confidence intervals overlapping occurred in the physical functioning categories for none and mild fatigue (Model A PFS-R no fatigue 95\% CI: $47.93-53.49$, mild fatigue $95 \%$ CI: 47.56 - 49.44). The $95 \%$ confidence intervals for the none and mild fatigue categories for the PFS-12 were very close (Model A PFS-12 no fatigue 95\% CI: 47.93 - 53.49, mild fatigue 95\% CI: 47.56 - 49.44). Breast cancer survivors with none and mild fatigue reported physical functioning scores similar to the mean U.S. population of women aged 55-64.

Model D for the PFS-12 showed similar results to Model A with confidence intervals overlapping for the categories of none and mild fatigue for physical functioning (Model D PFS-12 no fatigue $95 \%$ CI: 49.49 - 53.67, mild fatigue 95\% CI: $48.08-50.22$ ). However, Model D for the PFS-R was less able to discriminate between survivors categorized as none and mild fatigue. The domains of PCS, physical functioning, role physical, and social functioning had overlapping confidence intervals for the categories of none and mild fatigue when assessed by the PFS-R and Model D.

The mean score for sexual functioning was $0.43(\mathrm{SD}=0.57$ ) for pre-diagnosis and 0.88 $(\mathrm{SD}=0.80)$ for post-diagnosis. Figure 3 shows the incremental decrements in post-diagnosis sexual functioning that occurred as fatigue cut-scores increased. Model A for the PFS-R had overlapping confidence intervals for the categories of mild and moderate fatigue for lack of sexual interest; and moderate and severe fatigue for difficulty with arousal, inability to relax and enjoy sex, and difficulty with orgasm. Model A for the PFS-12 had overlapping confidence intervals for 2 of 4 sexual functioning items: mild and moderate fatigue for difficulty with arousal; and moderate and severe fatigue for difficulty with orgasm. Model D assessed by the PFS-R and PFS-12 had overlapping confidence intervals for the categories of mild and moderate for all 4 sexual functioning items: lack of sexual interest; difficulty with arousal; inability to relax and enjoy sex; and difficulty with orgasm.

Table 3 shows that approximately $40 \%$ of the variance in the PCS was explained by Models A and D for both the PFS-R and PFS-12. Approximately $30 \%$ of the variance in the MCS and sexual health was explained by Models A and D for the PFS-R and PFS-12.

As a sensitivity analysis, the cut-point models and associations with HRQOL were re-run excluding 57 women who experienced a cancer recurrence. Identical results were observed (data not shown) with the exception of larger confidence intervals for the severe fatigue category given fewer women in this category.

\section{Discussion}

We examined five models of fatigue severity cut-scores on the 22-item PFS-R and 12-item PFS-12 [37, 38] with a population-based cohort of breast cancer survivors approximately three years after diagnosis. Using the SF-36 Vitality subscale as a comparison measure for fatigue, two cut-score models showed the best discrimination among fatigue categories: A ( $0=$ no fatigue, $1-3=$ mild, $4-6=$ moderate, $7-10=$ severe fatigue $)$ and $\mathrm{D}(0=$ no fatigue, $1-$ $2=$ mild, $3-5=$ moderate, $6-10=$ severe fatigue). Severity levels of fatigue determined by Models A and D explained about $40 \%$ of the variance in the SF-36 PCS and about $30 \%$ in the MCS and sexual functioning. Previous research has primarily described the relationship between severity of fatigue and HRQOL in terms of correlational analyses [e.g., 52]. Our analyses extend this research by examining decrements in the HRQOL facets of physical, 
mental, and sexual functioning within each threshold for none, mild, moderate, and severe fatigue.

With only a few notable exceptions, we found that each threshold of worsening levels of fatigue in Models A and D was associated with statistically and clinically meaningful decrements in physical, mental, and sexual health, supporting the construct validity of these fatigue cut-scores in breast cancer survivors. On the whole, Model A for the PFS-12 where mild fatigue was conceptualized as $1-3$, moderate fatigue as $4-6$, and severe fatigue as $7-10$ demonstrated better discrimination than Model D for HRQOL decrements among breast cancer survivors. Moving forward, we recommend researchers and clinicians use Model A cut-points and the PFS-12 measure. The fatigue severity thresholds for Model A are preferred because they are clinically derived and consistent with conventions historically used for the PFS-R and other established fatigue and HRQOL measures that use an 11-point metric $[1,4,22,39]$. The PFS- 12 is recommended over the 22-item PFS as it has lower response burden but maintains reliable and valid measurement of fatigue [38].

Our results are consistent with prior research of predictors of sexual health such as comorbid conditions and emotional well-being [32-35]. Additional predictors with breast cancer survivors have been identified as vaginal dryness, body image, quality of partner relationship, and sexual problems with partner [30, 32-34]. Our study is distinctive in that fatigue cut-score models explained approximately $30 \%$ of the variance in sexual functioning, suggesting that fatigue should be explored as a predictor of sexual health and potential mutable intervention target.

This study had limitations. First, with respect to selection bias, the HEAL sample included a higher proportion with early stage and estrogen receptor-positive tumors than women eligible in SEER [39]. No demographic differences between enrolled and eligible women were found [39]. It may also be the case that the most fatigued women declined to enroll in HEAL. Given the large proportion of early stage tumors in HEAL (62\% Stages 0-1), only about $30 \%$ received chemotherapy, which is a prime risk factor for fatigue in breast cancer patients [57]. We attempted to more adequately represent the full range of fatigue severity, disease stage, and treatment regimens by including women who experienced a recurrence or new primary breast cancer. Future research should consider conducting prospective analyses assessing fatigue by treatment group, disease stage, and hormone receptor status.

Given the sampling design across SEER sites, significant differences in demographic characteristics existed between African-American and Caucasian survivor groups [1, 39]. Caucasian survivors were older and more likely to be married and have a college education while African American survivors were more likely to be working. There were also more deaths in the African-American group than Caucasian group before the HRQOL data was collected at 3 years post-diagnosis. This may be, in part, a function of tumor types. Women with triple negative disease (negative for hormone receptors and for HER2neu) tend to relapse early and can have early deaths, but recurrence rates decrease over time after diagnosis [58-60]. Women with hormone receptor-positive disease, which is most common in Caucasian women, tend to have a low but constant risk of recurrence [60]. In the MANCOVA and regression analyses, we controlled for race, age, education, stage, treatment type, tamoxifen and antidepressant use, and comorbid conditions in an effort to adjust for the influence of these factors.

Third, HEAL did not collect the PFS-R over time from diagnosis through survivorship and used a modified recall of one month (instead of one week) [1]. This extended recall period was intended to capture a general state of fatigue rather than acute episodes that may not be representative of survivors' overall fatigue experiences. Future research is needed to 
examine whether the cut-scores derived with a one-month recall period are also supported for a one-week timeframe. Future studies would also benefit from the inclusion of prospective fatigue measurement from women with all levels of fatigue, including very low and high levels. Such a study might be facilitated by measures that reduce respondent burden such as the PFS-12 [38].

A final limitation is that pre-diagnosis sexual health was assessed retrospectively. It may be that breast cancer survivors were more positive in recalling their sexual functioning before diagnosis than was actually the case. We controlled for pre-diagnosis sexual functioning in analyses examining post-diagnosis sexual health as an outcome.

Additional research is also needed to examine the extent to which empirically-derived cutscores of fatigue severity can be useful in designating case definitions of cancer-related fatigue (CRF) [13-16]. In addition to functional impairment, proposed criteria for case definitions of CRF must necessarily take into account the presence of alternative proximal causes for fatigue such as an endocrine disorder like hypothyroidism or a psychiatric disorder like depression. This study did not assess emotional distress beyond the SF-36 and antidepressant use. Psychometrically developed measures of emotional distress such as the Depression, Anxiety, and Anger item banks developed by the Patient-Reported Outcomes Measurement Information System ${ }^{\circledR}$ (PROMIS ${ }^{\circledR}$ ) may be informative for these purposes [61].

Two larger questions remain: 1.) Whether the cut-points identified for the PFS-R and PFS-12 result in comparable groupings of individuals with equivalent levels of fatigue severity when compared to other instruments; and 2.) Whether breast cancer survivors identify the cut-scores as meaningful to them? These answers would be important to move our field forward and enhance communication and reproducibility of results in cancer fatigue research.

\section{Acknowledgments}

The parent HEAL Study was supported by NCI contracts N01-CN-75036-20, N01-CN-05228, and N01-PC-67010. The first author is supported by a UNC Lineberger Comprehensive Cancer Center Cancer Control and Education (CCEP) Predoctoral Fellowship (5R25-CA057726).

\section{Acronyms}

$\begin{array}{ll}\text { BMI } & \text { Body Mass Index } \\ \text { CIPS } & \text { Cancer Inventory for Problem Situations } \\ \text { CRF } & \text { Cancer-related fatigue } \\ \text { HEAL } & \text { Health, Eating, Activity, and Lifestyle Study } \\ \text { HRQOL } & \text { Health-Related Quality of Life } \\ \text { MANCOVA } & \text { Multivariate Analysis of Covariance } \\ \text { MCS } & \text { Mental Component Score for the SF-36 } \\ \text { PCS } & \text { Physical Component Score for the SF-36 } \\ \text { PFS-R } & \text { Piper Fatigue Scale- Revised } \\ \text { PFS-12 } & \text { Piper Fatigue Scale-12 } \\ \text { SEER } & \text { Surveillance, Epidemiology, and End Results (cancer registries) }\end{array}$


SF-36 Medical Outcomes Study Short Form-36

\section{References}

1. Meeske K, Smith AW, Alfano CM, McGregor BA, McTiernan A, Baumgartner KB, et al. Fatigue in breast cancer survivors two to five years post diagnosis: a HEAL Study report. Quality of Life Research. 2007; 16:947-960. [PubMed: 17457697]

2. Kim J-E, Dodd MJ, Aouizerat BE, Jahan T, Miaskowski C. A review of the prevalence and impact of multiple symptoms in oncology patients. Journal of Pain and Symptom Management. 2009; 37:715-736. [PubMed: 19019626]

3. Scott JA, Lasch K, Barsevick A, Piault-Louis E. Patient-reported Outcomes of Fatigue Consortium (PROOF-C). Patients' Experiences with cancer-related fatigue: A systematic review and synthesis of qualitative research. Oncology Nursing Forum. 2011; 38:E191-E203. [PubMed: 21531669]

4. Ganz PA, Desmond KA, Leedham B, Rowland JH, Meyerowitz BE, Belin TR. Quality of life in long-term, disease-free survivors of breast cancer: a follow-up study. Journal of the National Cancer Institute. 2002; 94:39-49. [PubMed: 11773281]

5. Mitchell S. Cancer-related fatigue: State of the science. Physical Medicine and Rehabilitation. 2010; 2:364-383.

6. Piper BF, Cella D. Cancer-related fatigue: definitions and clinical subtypes. Journal of the National Comprehensive Cancer Network. 2010; 8:958-966. [PubMed: 20870639]

7. Knowles G, Borthwick D, McNamara S, Miller M, Leggot L. Survey of nurses' assessment of cancer-related fatigue. European Journal of Cancer Care. 2000; 9:105-113. [PubMed: 11261011]

8. Pachman DR, Barton DL, Swetz KM, Loprinzi CL. Troublesome symptoms in cancer survivors: fatigue, insomnia, neuropathy, and pain. Journal of Clinical Oncology. 2012; 30:3687-3696. [PubMed: 23008320]

9. Barsevick AM, Cleeland CS. ASCPRO Recommendations for the assessment of fatigue as an outcome in clinical trials. Journal of Pain and Symptom Management. 2010; 39:1086-1099. [PubMed: 20538190]

10. The Cancer-Related Fatigue Guidelines (Version 4.2007) in The Complete Library of NCCN Clinical Practice Guidelines in Oncology [CD-ROM] Jenkintown, Pennsylvania: (C) 2006 National Comprehensive Cancer Network, Inc.; Mar, 2008. To view the most recent and complete version of the guideline. go to www.ncen.org

11. Berger AM, Abernethy AP, Atkinson A. Cancer-related fatigue. JNCCN. 2010; 8:904-931. [PubMed: 20870636]

12. Mitchell, SA.; Beck, SL.; Eaton, LH. ONS Putting Evidence Into Practice (PEP): Fatigue. In: Eaton, LH.; Tipton, JM., editors. Putting evidence into practice. Pittsburgh: Oncology Nursing Society; 2009.

13. Cella D, Davis K, Breitbart W, Curt G. for the Fatigue Coalition. Cancer-related fatigue: Prevalence of proposed diagnostic criteria in a United States sample of cancer survivors. Journal of Clinical Oncology. 2001; 19:3385-3391. [PubMed: 11454886]

14. Cella D, Peterman A, Passik S, et al. Progress towards guidelines for the management of fatigue. Oncology. 1998; 12:369-377. [PubMed: 10028520]

15. Vogelzang N, Breitbart W, Cella D, et al. Patient, caregiver, and oncologist perceptions of cancerrelated fatigue: Results of a tri-part assessment survey. Semin Hematol. 1997; 34(Supplement 2): 4-12. [PubMed: 9253778]

16. Agasi-Idenburg C, Velthuis M, Wittink H. Quality criteria and user-friendliness in self-reported questionnaires on cancer-related fatigue: a review. Journal of Clinical Epidemiology. 2010; 63:705-711. [PubMed: 20172691]

17. Dittner AJ, Wessely SC, Brown RG. The assessment of fatigue: a practical guide for clinicians and researchers. Journal of Psychosomatic Research. 2004; 56:157-170. [PubMed: 15016573]

18. Jean-Pierre P, Figueroa-Moseley CD. Assessment of cancer-related fatigue: implications for clinical diagnosis and treatment. Oncologist. 2007; 12(Supplement 1):11-21. [PubMed: 17573452] 
19. Minton O, Stone P. A systematic review of the scales used for the measurement of cancer-related fatigue (CRF). Annals of Oncology. 2009; 20:17-25. [PubMed: 18678767]

20. Mota DD, Pimenta CA. Self-report instruments for fatigue assessment: a systematic review. Research and Theory for Nursing Practice. 2006; 20:49-78. [PubMed: 16544894]

21. Whitehead L. The measurement of fatigue in chronic illness: a systematic review of unidimensional and multidimensional fatigue measures. Journal of Pain and Symptom Management. 2009; 37:107-128. [PubMed: 19111779]

22. Mendoza T, Wang XS, Cleeland CS, Morrissey M, Johnson BA, Wendt JK, et al. The Rapid Assessment of Fatigue Severity in Cancer Patients: Use of the Brief Fatigue Inventory. Cancer. 1999; 85:1186-1196. [PubMed: 10091805]

23. Borneman T, Koczywas M, Sun VC, Piper BF, Uman G, Ferrell B. Reducing patient barriers to pain and fatigue management. Journal of Pain and Symptom Management. 2010; 39:486-501. [PubMed: 20303026]

24. Weilgus K, Berger AM, Hertzog M. Predictors of fatigue 30 days after completing anthracycline plus taxane adjuvant chemotherapy for breast cancer. Oncology Nursing Forum. 2009; 36:38-48. [PubMed: 19136337]

25. Cullum JL, Wojciechowski AE, Simpson JSA. Bupropion sustained release treatment reduces fatigue in cancer patients. Canadian Journal of Psychiatry. 2004; 49:139-144.

26. Cooper MR, Bird HM, Steinberg M. Efficacy and safety of Modafinil in the treatment of CancerRelated Fatigue. The Annals of Pharmacotherapy. 2009; 43:721-725. [PubMed: 19318599]

27. Jean-Pierre P, Morrow GR, Roscoe JA, Heckler C, Mohile S, Janelsins M, et al. A phase 3 randomized, placebo-controlled, doubleblind, clinical trial of the effect of modafinil on cancerrelated fatigue among 631 patients receiving chemotherapy: A University of Rochester Cancer Center Community Clinical Oncology Program Research base study. Cancer. 2010; 116:35133520. [PubMed: 20564068]

28. Moss EL, Simpson JS, Pelletier G, et al. An open-label study of the effects of bupropion SR on fatigue, depression and quality of life of mixed-site cancer patients and their partners. Psychooncology. 2006; 15:259-267. [PubMed: 16041840]

29. Nering, ML.; Ostini, R. Handbook of polytomous item response theory models. New York, NY: Routledge; 2010.

30. Chamberlain Wilmoth M, Coleman EA, Smith SC, Davis C. Fatigue, weight gain, and altered sexuality in patients with breast cancer: Exploration of a symptom cluster. Oncology Nursing Forum. 2004; 31:1069-1075. [PubMed: 15547630]

31. Webber K, Mok K, Bennett B, Lloyd AR, Friedlander M, Juraskova I, et al. If I am in the mood, I enjoy it: An exploration of Cancer-Related Fatigue and sexual functioning in women with breast cancer. The Oncologist. 2011; 16:1333-1344. [PubMed: 21835897]

32. Ganz PA, Rowland JH, Desmond K, Meyerowitz BE, Wyatt GE. Life after breast cancer: understanding women's health-related quality of life and sexual functioning. Journal of Clinical Oncology. 1998; 16:501-514. [PubMed: 9469334]

33. Ganz PA, Desmond KA, Belin TR, Meyerowitz BE, Rowland JH. Predictors of sexual health in women after a breast cancer diagnosis. Journal of Clinical Oncology. 1999; 17:2371-2380. [PubMed: 10561299]

34. Fobair, P.; Spiegel, D. Concerns about sexuality after breast cancer. In: Devita, VT.; Lawrence, TS.; Rosenberg, SA., editors. Cancer principles and practice of oncology: Annual advances in oncology. Philadelphia, PA: Lippincott Williams \& Wilkins; 2010. p. 7-14.

35. Lindau ST, Schumm LP, Laumann EO, Levinson W, O'Muircheartaigh CA, Waite LJ. A study of sexuality and health among older adults in the United States. New England Journal of Medicine. 2007; 357:762-774. [PubMed: 17715410]

36. Rubin, P. Clinical oncology: A multidisciplinary approach for physicians and students. 8th ed. Philadelphia, PA: W.B. Saunders Company; 2001.

37. Piper BF, Dibble SL, Dodd MJ, Weiss MC, Slaughter RE, Paul SM. The revised Piper Fatigue Scale: psychometric evaluation in women with breast cancer. Oncology Nursing Forum. 1998; 25:677-684. [PubMed: 9599351] 
38. Reeve BB, Stover AM, Alfano CM, Piper BF, Bernstein L, Baumgartner K, et al. Psychometric Evaluation and Reduction of the Piper Fatigue Scale Based on a Cohort of Breast Cancer Survivors. Breast Cancer Research \& Treatment. 2012; 136:9-20. [PubMed: 22933027]

39. McTiernan A, Rajan KB, Tworoger SS, Irwin M, Bernstein L, Baumgartner R, et al. Adiposity and sex hormones in postmenopausal breast cancer survivors. Journal of Clinical Oncology. 2003; 21:1961-1966. [PubMed: 12743149]

40. Groenvold M, Aagard Petersen M, Idler E, Bjorner JB, Fayers PM, Mouridsen HT. Psychological distress and fatigue predicted recurrence and survival in primary breast cancer patients. Breast Cancer Research and Treatment. 2007; 105:209-219. [PubMed: 17203386]

41. Ware JE, Sherbourne CD. The MOS 36-item short-form health survey (SF-36)IConceptual framework and item selection. Medical Care. 1992; 30:473-483. [PubMed: 1593914]

42. Schag CAC, Heinrich RL, Aadland RL, Ganz PA. Assessing problems of cancer patients: Psychometric properties of the Cancer Inventory of Problem Situations (CIPS). Health Psychology. 1990; 9:83-102. [PubMed: 2323331]

43. Bjorner JB, Wallenstein GV, Martin MC, Lin P, Blaisdell-Gross, Piech CT, et al. Interpreting score differences in the SF-36 Vitality scale: using clinical conditions and functional outcomes to define the minimally important difference. Current Medical Research and Opinions. 2007; 23:731-739.

44. Norman GR, Sloan JA, Wyrwich KW. Interpretation of changes in health-related quality of life: the remarkable universality of half a standard deviation. Medical Care. 2003; 41:582-92. [PubMed: 12719681]

45. Revicki D, Hays R, Cella D, Sloan J. Recommended methods for determining responsiveness and minimally important differences for patient-reported outcomes. Journal of Clinical Epidemiology. 2008; 61:102-109. [PubMed: 18177782]

46. Sloan J, Cella D, Hays R. Clinical significance of patient-reported questionnaire data: another step toward consensus. Journal of Clinical Epidemiology. 2005; 58:1217-1219. [PubMed: 16291464]

47. Schwartz AL, Meek PM, Nail L, Fargo J, Lundquist M, Donofrio M, et al. Measurement of fatigue: determining minimally important differences. Journal of Clinical Epidemiology. 2002; 55:239-244. [PubMed: 11864794]

48. American Joint Committee on Cancer. AJCC cancer staging handbook. 7th edition. Chicago, IL: Author; 2010.

49. Hand, DJ.; Taylor, CC. Multivariate analysis of variance and repeated measures. London: Chapman and Hall; 1987.

50. Davies, N.; Gibbons, E.; Mackintosh, A.; Fitzpatrick, R. on behalf of the Oxford Patient-Reported Outcomes Measurement Group. A structured review of patient-reported outcome measures (PROMs) for women with breast cancer. Oxford: University of Oxford; 2009.

51. Ganz PA, Desmond KA, Leedham B, Rowland JH, Meyerowitz BE, Belin TR. Quality of life in long-term, disease-free survivors of breast cancer: A follow-up study. Journal of the National Cancer Institute. 2002; 94:39-49. [PubMed: 11773281]

52. Wilson RW, Hutson LM, VanStry D. Comparison of 2 Quality-of-Life Questionnaires in women treated for breast cancer: The RAND 36-Item Health Survey and the Functional Living IndexCancer. Physical Therapy. 2005; 85:851-860. [PubMed: 16117596]

53. Bower JE, Ganz PA, Desmond KA, Rowland JH, Meyerowitz BE, Belin TR. Fatigue in Breast Cancer Survivors: Occurrence, Correlates, and Impact on Quality of Life. Journal of Clinical Oncology. 2000; 18:743-749. [PubMed: 10673515]

54. Merle ME. Correlates of fatigue in survivors of breast cancer. Cancer Nursing. 1998; 21:136-142. [PubMed: 9556940]

55. Haghighat S, Esmail Akbari M, Holakouei K, Rahimi A, Montazeri A. Factors predicting fatigue in breast cancer patients. Supportive Care in Cancer. 2003; 11:533-538. [PubMed: 12730728]

56. Day R, Ganz PA, Costantino JP, Cronin WM, Wickerman DL, Fisher B. Health-Related Quality of Life and tamoxifen in breast cancer prevention: A Report from the National Surgical Adjuvant Breast and Bowel Project P-1 Study. Journal of Clinical Oncology. 1999; 17:2659-2669. [PubMed: 10561339] 
57. de Jong N, Courtens AM, Abu-Saad HH, Schouten HC. Fatigue in patients with breast cancer receiving adjuvant chemotherapy: A review of the literature. Cancer Nursing. 2002; 25:283-297. [PubMed: 12181497]

58. Lin NU, Vanderplas A, Hughes ME, Theriault RL, Edge SB, Wong Y-N, et al. Clinicopathologic features, patterns of recurrence, and survival among women with triple-negative breast cancer in the National Comprehensive Cancer Network. Cancer. 2012; 118:5463-5472. [PubMed: 22544643]

59. Rakka EA, El-Sayed ME, Green AR, Lee AHS, Robertson JF, Ellis IO. Prognostic markers in triple-negative breast cancer. Cancer. 2007; 109:25-32. [PubMed: 17146782]

60. Anderson WF, Chu KC, Chatterjee N, Brawley O, Brinton LA. Tumor variants by hormone receptor expression in white patients with node-negative breast cancer from the Surveillance, Epidemiology, and End Results database. Journal of Clinical Oncology. 2001; 19:18-27. [PubMed: 11134191]

61. Pilkonis PA, Choi SW, Reise SP, Stover AM, Riley WT, Cella D. Item banks for measuring emotional distress from the Patient-Reported Outcomes Measurement Information System (PROMIS): depression, anxiety, \& anger. Assessment. 2011; 18:263-283. [PubMed: 21697139] 

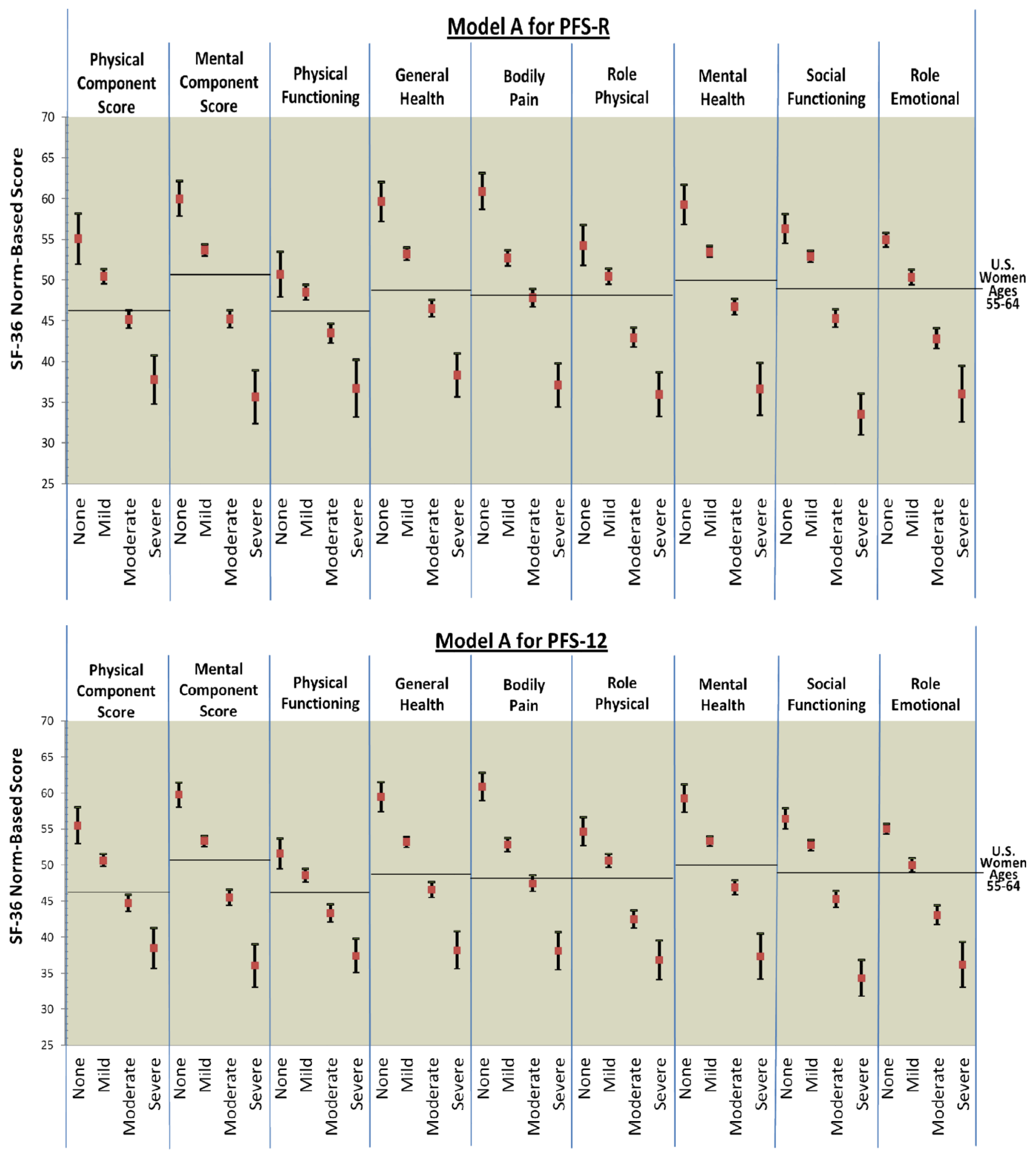

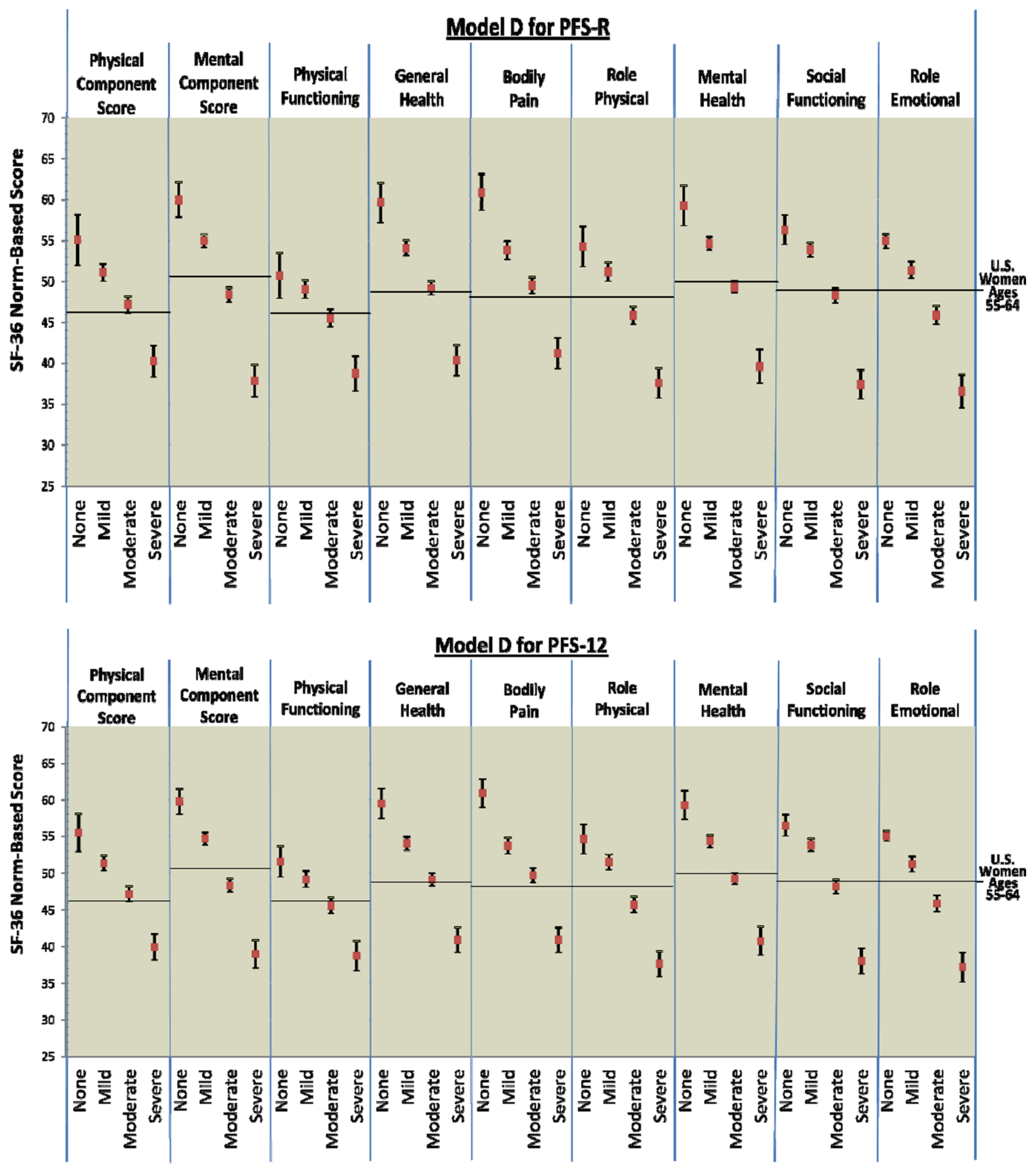

Figure 1.

PFS-R and PFS-12 Models A and D Fatigue Severity Cut-Scores and Decrements in Physical and Mental Health 
* Model A Fatigue Severity Cut-Scores: 0 (no fatigue), 1-3 (mild), 4-6 (moderate), 7-10 (severe fatigue)

** Model D Fatigue Severity Cut-Scores: 0 (no fatigue), 1-2 (mild), 3-5 (moderate), 6-10 (severe fatigue) 

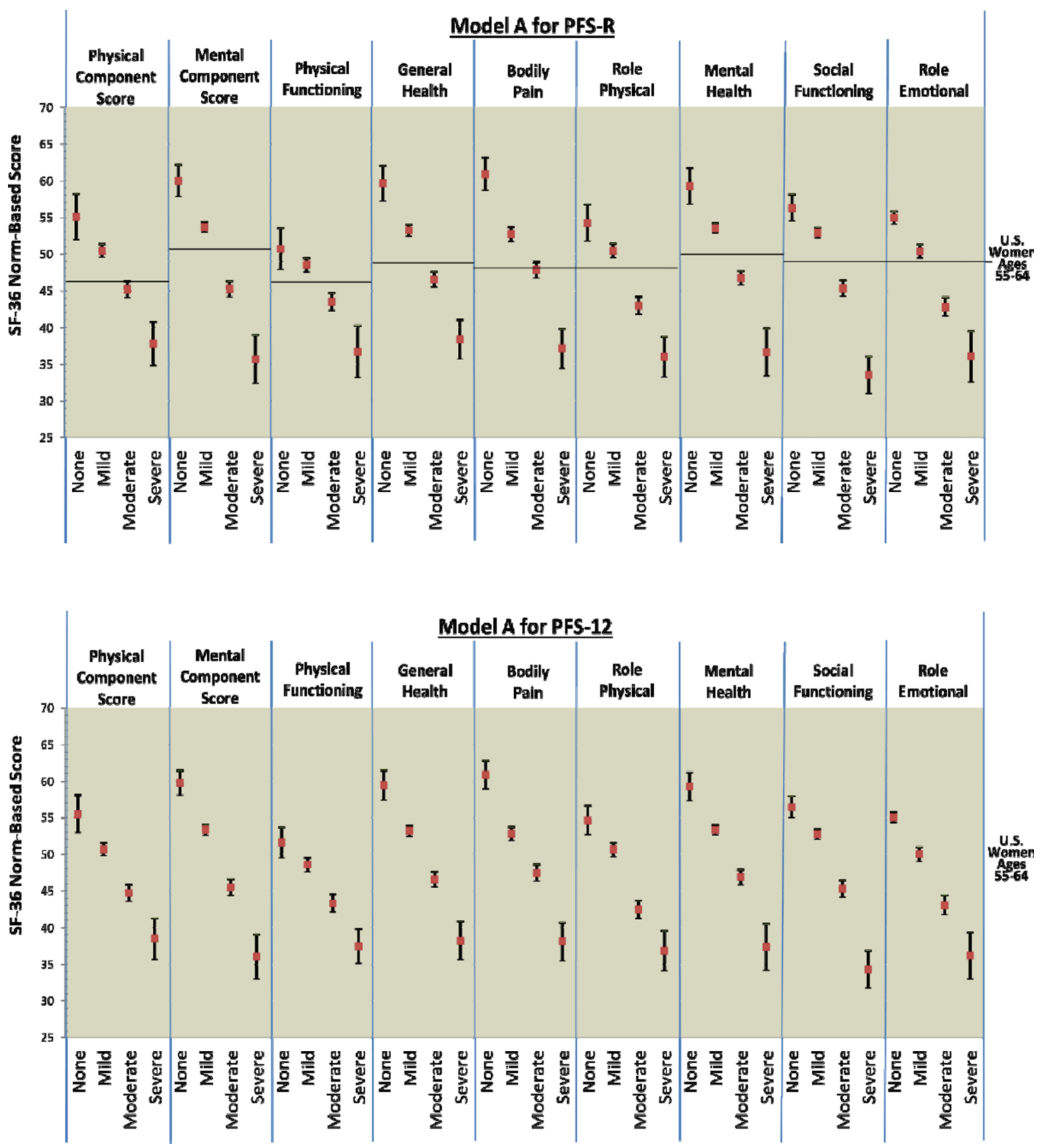

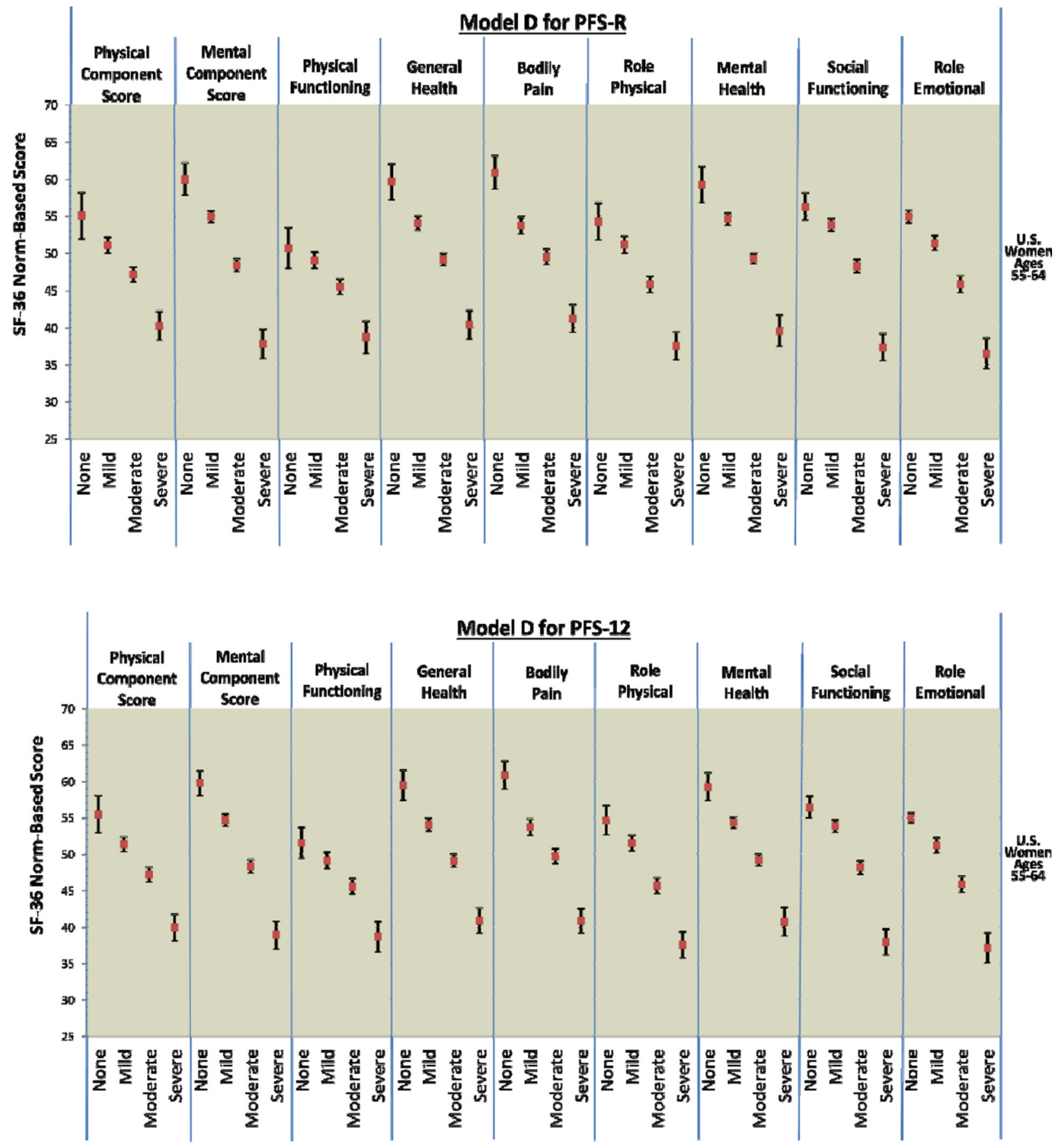

Figure 2.

PFS-R and PFS-12 Models A and D Fatigue Severity Cut-Scores and Decrements in Physical and Mental Health

* Model A Fatigue Severity Cut-Scores: 0 (no fatigue), 1-3 (mild), 4-6 (moderate), 7-10 (severe fatigue)

* Model D Fatigue Severity Cut-Scores: 0 (no fatigue), 1-2 (mild), 3-5 (moderate), 6-10 (severe fatigue) 


\section{Lack of Sexual Interest}
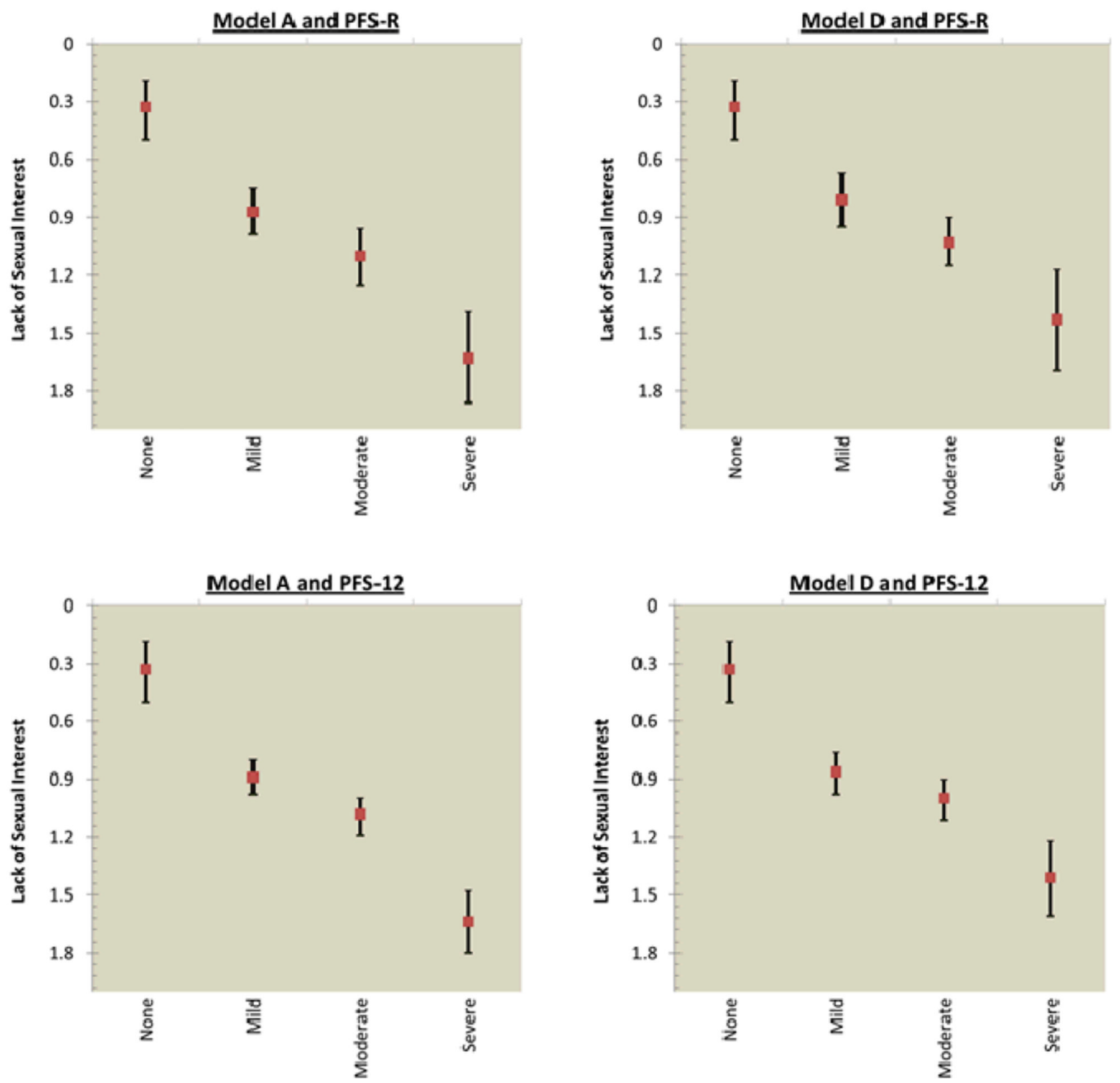


\section{Difficulty with Arousal}
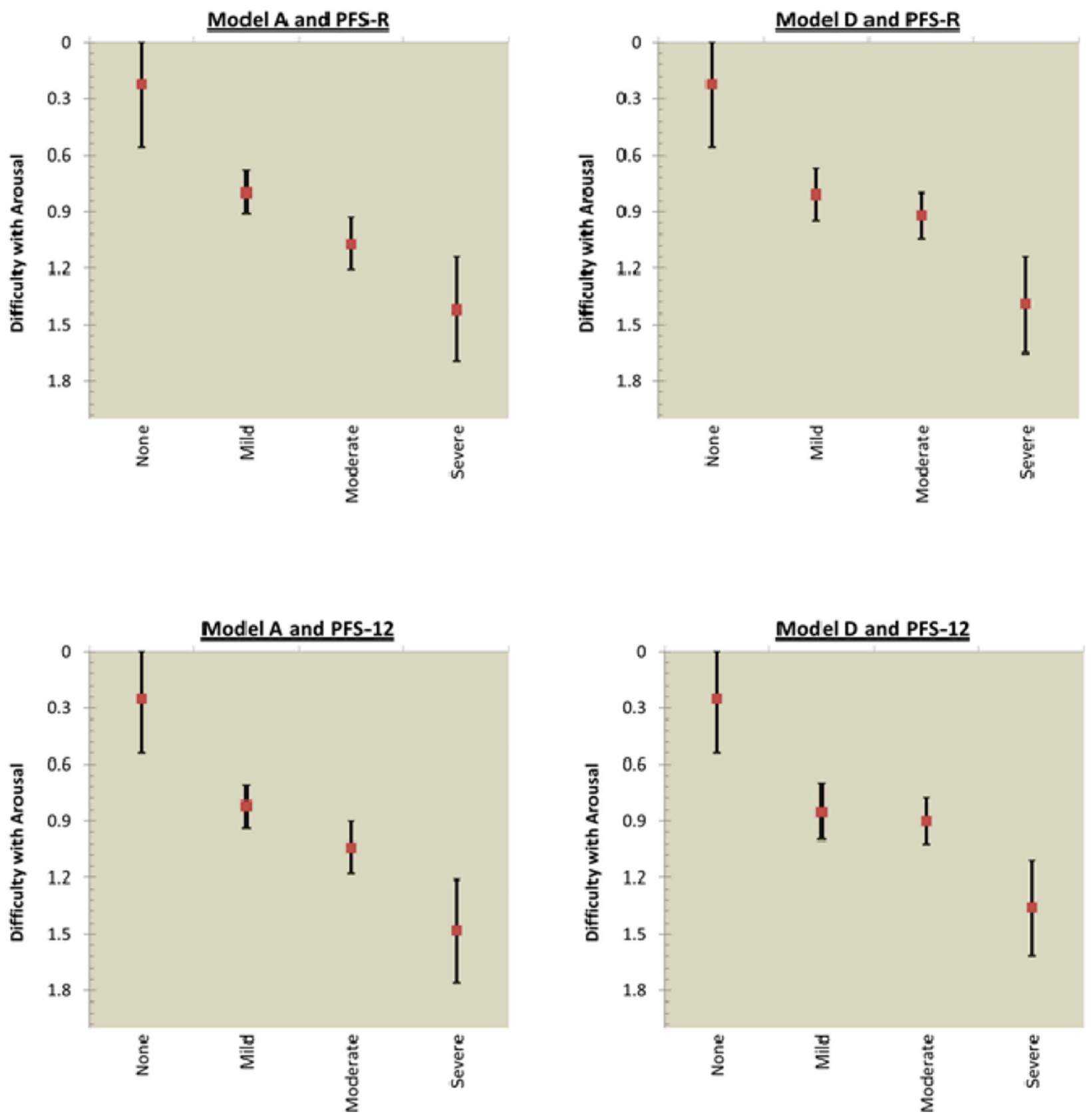


\section{Inability to Relax and Enjoy Sex}



\section{Difficulty with Orgasm}
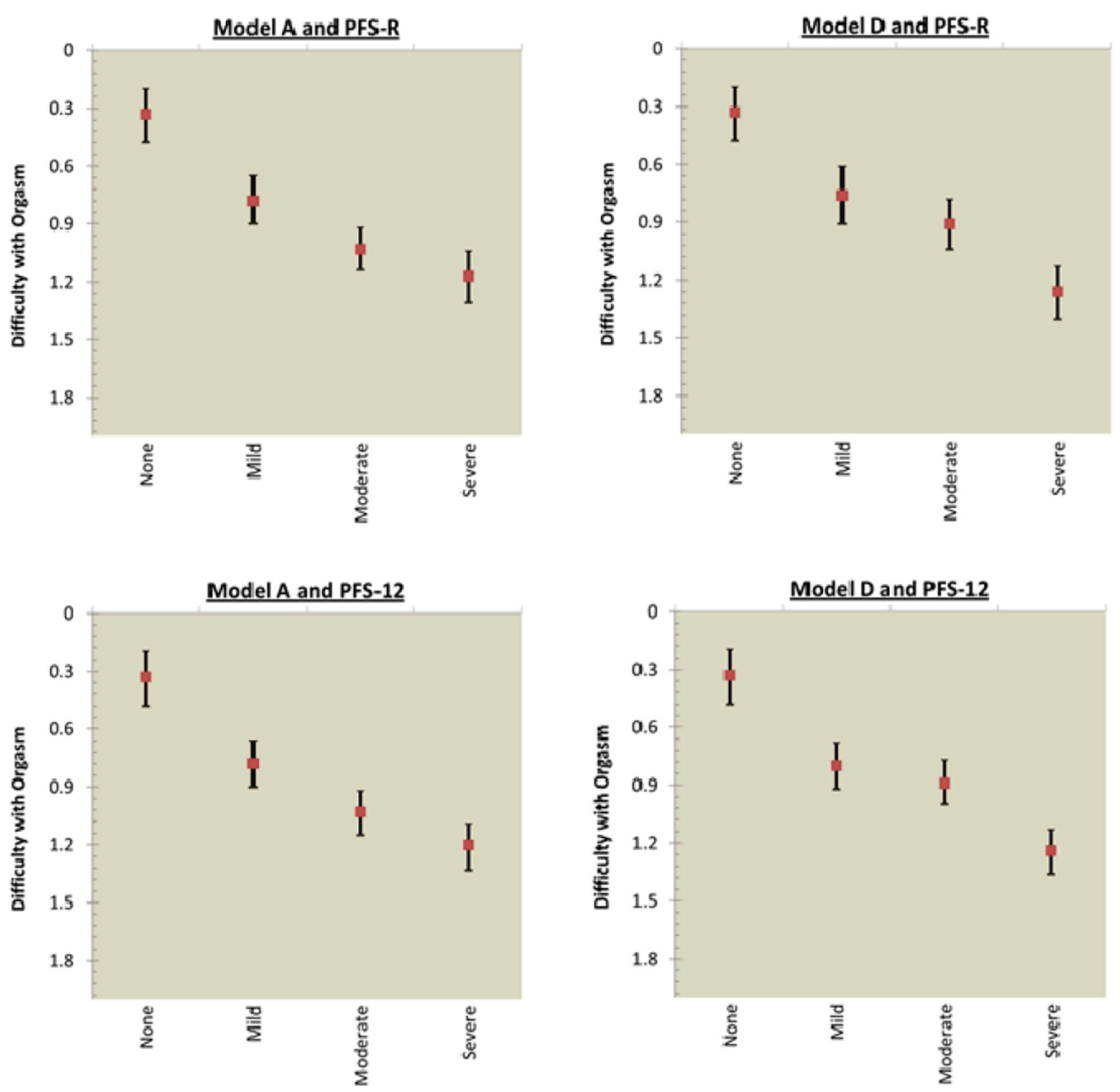

Figure 3.

PFS-R and PFS-12 Models A and D Fatigue Severity Cut-Scores and Decrements in Sexual Health

* Model A Fatigue Severity Cut-Scores: 0 (no fatigue), 1-3 (mild), 4-6 (moderate), 7-10 (severe fatigue)

** Model D Fatigue Severity Cut-Scores: 0 (no fatigue), 1-2 (mild), 3-5 (moderate), 6-10 (severe fatigue) 
Table 1

Sample \& Clinical Characteristics at Follow-Up Interview (N=857)

\begin{tabular}{|c|c|c|c|}
\hline Demographics & $\begin{array}{c}\mathbf{N}(\%) \text { or } \\
\text { Mean } \pm \text { SD }\end{array}$ & Clinical Characteristics & $\begin{array}{c}\mathbf{N}(\%) \text { or } \\
\text { Mean } \pm \text { SD }\end{array}$ \\
\hline \multicolumn{2}{|l|}{ Age at Diagnosis } & \multicolumn{2}{|l|}{ Stage of Breast Cancer } \\
\hline Mean age \pm SD & $55.29 \pm 10.31$ & In situ-Stage 0 & $193(22 \%)$ \\
\hline \multicolumn{2}{|l|}{ Marital Status } & Localized-Stage I & $342(40 \%)$ \\
\hline Married & $473(57 \%)$ & Regional-Stage II a & $160(19 \%)$ \\
\hline Widowed & $105(13 \%)$ & Stage II b & $82(10 \%)$ \\
\hline Divorced/Separated & $190(22 \%)$ & Stage III a & $19(2 \%)$ \\
\hline Never Married & $57(7 \%)$ & Unstaged & $60(7 \%)$ \\
\hline \multicolumn{2}{|l|}{ Education } & \multicolumn{2}{|l|}{ Adjuvant Therapy } \\
\hline$\leq$ High School Graduate & $218(25 \%)$ & None & $274(32 \%)$ \\
\hline Some College & $311(36 \%)$ & Radiation Therapy & $313(37 \%)$ \\
\hline College Graduate & $166(19 \%)$ & Chemotherapy & $82(9 \%)$ \\
\hline Graduate School & $161(19 \%)$ & Radiation Therapy and Chemotherapy & $188(22 \%)$ \\
\hline \multicolumn{2}{|l|}{ Employment Status } & \multicolumn{2}{|l|}{ Surgery } \\
\hline Working & $474(57 \%)$ & No Surgical Procedure & $14(2 \%)$ \\
\hline Not working - leave, retired, unemployed & $319(37 \%)$ & Partial Mastectomy & $552(64 \%)$ \\
\hline Not working - disabled & $33(4 \%)$ & Total/modified Mastectomy & $290(34 \%)$ \\
\hline \multicolumn{2}{|l|}{ Income } & \multicolumn{2}{|l|}{ Tamoxifen at follow-up } \\
\hline$\leq 20,000$ & $148(18 \%)$ & No & $460(56 \%)$ \\
\hline $20,001-50,000$ & $284(33 \%)$ & Yes & $368(44 \%)$ \\
\hline $50,001-70,000$ & $222(27 \%)$ & & \\
\hline$\geq 70,000$ & $118(14 \%)$ & & \\
\hline \multicolumn{2}{|l|}{ Race/Ethnicity } & \multicolumn{2}{|l|}{ Lymphedema } \\
\hline Non-Hispanic Caucasian & $506(67 \%)$ & Never & $681(79 \%)$ \\
\hline Non-Hispanic African American & $224(30 \%)$ & Yes, not current & $49(6 \%)$ \\
\hline Non-Hispanic Other & $25(3 \%)$ & Yes, current & $127(15 \%)$ \\
\hline Ethnicity: Hispanic & $102(12 \%)$ & & \\
\hline \multicolumn{2}{|l|}{ Menopausal Status } & \multicolumn{2}{|c|}{ Bothered by Lymphedema in Past 3 Months } \\
\hline Post-menopausal & $628(76 \%)$ & Not at all & $49(28 \%)$ \\
\hline Pre-menopausal & $151(18 \%)$ & A little/ A fair amount & $108(61 \%)$ \\
\hline Unclassifiable & $49(6 \%)$ & Much/Very much & $19(11 \%)$ \\
\hline \multicolumn{2}{|l|}{ Smoking Status } & \multicolumn{2}{|l|}{ BMI } \\
\hline Not at all (or N/A) & $729(85 \%)$ & $<25$ & $377(44 \%)$ \\
\hline Every day & $71(9 \%)$ & $25-29$ & $239(28 \%)$ \\
\hline On some days & $28(3 \%)$ & 230 & $241(28 \%)$ \\
\hline \multicolumn{2}{|l|}{ Comorbidities } & \multicolumn{2}{|l|}{ SEER Site } \\
\hline 0 & $215(26 \%)$ & New Mexico & $457(53 \%)$ \\
\hline
\end{tabular}




\begin{tabular}{|c|c|c|c|}
\hline Demographics & $\begin{array}{c}\mathbf{N}(\%) \text { or } \\
\text { Mean } \pm \text { SD }\end{array}$ & Clinical Characteristics & $\begin{array}{c}\mathbf{N}(\%) \text { or } \\
\text { Mean } \pm \text { SD }\end{array}$ \\
\hline $1-2$ & $400(47 \%)$ & Western Washington State & $177(21 \%)$ \\
\hline 23 & $213(25 \%)$ & Los Angeles County & $223(26 \%)$ \\
\hline \multicolumn{2}{|c|}{ \# Comorbid Conditions that Limit Activities } & \multicolumn{2}{|l|}{ Hormone Receptors } \\
\hline 0 & $618(75 \%)$ & Estrogen receptor positive $(\mathrm{ER}+)$ & $480(56 \%)$ \\
\hline 1 & $145(18 \%)$ & Progesterone receptor positive $(\mathrm{PR}+)$ & $386(45 \%)$ \\
\hline 2 & $38(5 \%)$ & \multicolumn{2}{|l|}{ Antidepressants at Follow-Up } \\
\hline $3-4$ & $27(2 \%)$ & Yes & $128(15 \%)$ \\
\hline
\end{tabular}




\begin{tabular}{|c|c|c|c|c|c|c|c|c|c|c|c|c|c|}
\hline \multirow{3}{*}{ 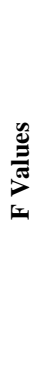 } & 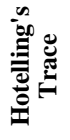 & $\begin{array}{c}\tilde{m} \\
\dot{\delta}\end{array}$ & $\begin{array}{l}\text { त̂ } \\
\text { ఫ̦ }\end{array}$ & $\begin{array}{l}\hat{a} \\
\dot{\gamma}\end{array}$ & 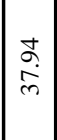 & $\left|\begin{array}{l}0 \\
\dot{n} \\
\dot{m}\end{array}\right|$ & \multirow{3}{*}{ 总 } & 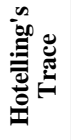 & 굴 & 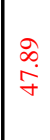 & $\begin{array}{l}\stackrel{ }{9} \\
\dot{g}\end{array}$ & $\begin{array}{l}\hat{N} \\
\dot{a}\end{array}$ & $\begin{array}{l}\vec{\alpha} \\
\dot{0} \\
\dot{m}\end{array}$ \\
\hline & 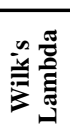 & $\stackrel{R}{\stackrel{f}{+}}$ & 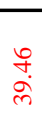 & 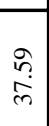 & \begin{tabular}{|c|c}
$\infty$ \\
$\stackrel{1}{0}$ \\
$\tilde{m}$
\end{tabular} & $\begin{array}{c}\tilde{c} \\
\tilde{r} \\
\tilde{m}\end{array}$ & &  & $\mid \begin{array}{l}\tilde{\infty} \\
\stackrel{j}{\sigma}\end{array}$ & 官 & $\begin{array}{l}0 \\
\substack{1 \\
\infty \\
\infty}\end{array}$ & $\begin{array}{l}\hat{a} \\
\dot{j}\end{array}$ & $\begin{array}{l}m \\
\vec{i} \\
\vec{m}\end{array}$ \\
\hline & 苋 & $\vec{\infty}$ & $\begin{array}{l}\text { : } \\
\text { î. } \\
\text { mे }\end{array}$ & $\frac{\vec{N}}{\bar{m}}$ & \begin{tabular}{|c|}
$\hat{f}$ \\
$\dot{d}$ \\
$i$
\end{tabular} & $\begin{array}{l}\tilde{\theta} \\
\dot{d} \\
\end{array}$ & & 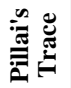 & \begin{tabular}{|l}
$\infty$ \\
0 \\
$\dot{m}$
\end{tabular} & mે & $\frac{\tilde{\infty}}{\dot{m}}$ & $\begin{array}{l}\text { i̊ } \\
\text { ते }\end{array}$ &  \\
\hline \multirow{5}{*}{ 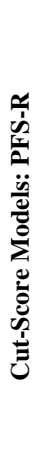 } & 离 & $\frac{\rho}{b}$ & $\frac{0}{1}$ & $\stackrel{0}{\circ}$ & $\frac{0}{1}$ & $\frac{0}{1}$ & \multirow{5}{*}{ 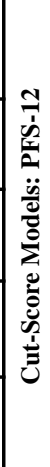 } & 蒂 & ] & $\frac{0}{1}$ & $\frac{0}{1}$ & $\frac{0}{1}$ & $\begin{array}{l}0 \\
\frac{1}{\infty}\end{array}$ \\
\hline & $\stackrel{\Xi}{\Delta}$ & s. & $q$ & I & $\begin{array}{l}0 \\
1 \\
m\end{array}$ & in & & $\sum_{\Sigma}^{\circ}$ & 1n & $\begin{array}{l}0 \\
q\end{array}$ & F & $\begin{array}{l}0 \\
1 \\
m\end{array}$ & i \\
\hline & $\frac{\pi}{2}$ & $I$ & I & $I$ & $I$ & $I$ & & $\frac{\pi}{\bar{z}}$ & $I$ & $I$ & $I$ & $I$ & $I$ \\
\hline & 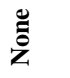 & $\theta$ & 0 & 0 & 0 & 0 & & 言 & 0 & 0 & 0 & 0 & 0 \\
\hline & $\frac{\bar{d}}{\frac{\pi}{2}}$ & $\theta$ & $\ll$ & 0 & $\omega$ & $\infty$ & & $\frac{\bar{\Xi}}{\frac{\mathrm{J}}{2}}$ & 0 & $\ll$ & 0 & $\omega$ & $\infty$ \\
\hline
\end{tabular}




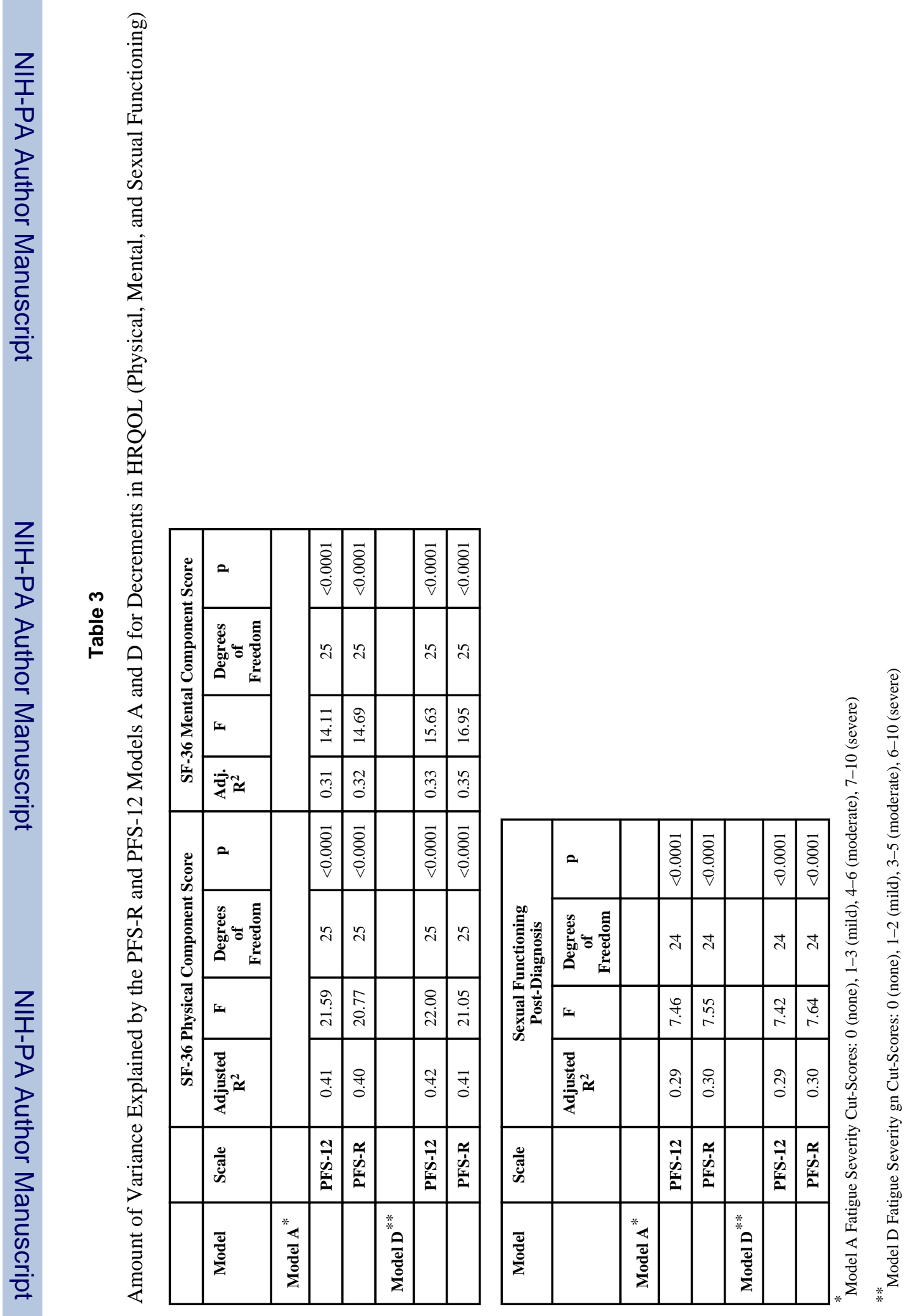

